\title{
Characterization of Surface Vanadia Forms on V/Ti-Oxide Catalyst via Temperature-Programmed Reduction in Hydrogen and Spectroscopic Methods
}

\author{
Dmitri A. Bulushev, Lioubov Kiwi-Minsker, ${ }^{1}$ Fabio Rainone, and Albert Renken \\ Swiss Federal Institute of Technology, LGRC-EPFL, CH-1015 Lausanne, Switzerland
}

Received June 4, 2001; revised September 28, 2001; accepted October 1, 2001

Surface vanadia species formed on vanadia/titania catalysts consisting of 0.2-2.6 monolayers (ML) of $\mathrm{VO}_{x}$ have been characterized by FT-Raman spectroscopy under controlled atmosphere, temperature-programmed reduction in hydrogen (TPR), and solubility in diluted $\mathrm{HNO}_{3}$. Three types of species were observed with the maximum peak temperatures as follows: isolated monomeric species $(\leq 770-780 \mathrm{~K})$, polymeric species $(810$ $\mathrm{K})$, and bulk amorphous $\mathrm{V}_{2} \mathrm{O}_{5}(852 \mathrm{~K})$. During the reduction, the $\mathrm{V}=\mathrm{O}$ bond of the monomeric species with tetracoordinated vanadium disappears as shown by diffuse reflectance infrared Fourier transform spectroscopy. A formation of new hydroxyl groups with a basic character was observed. The monomeric species was found to be chemically stable with respect to diluted $\mathrm{HNO}_{3}$. Bulk amorphous $\mathrm{V}_{2} \mathrm{O}_{5}$ and polymeric vanadia were soluble in $\mathrm{HNO}_{3}$ and removed from the surface. The state of vanadium in the oxidized catalysts was mainly pentavalent, as shown by XPS, and did not change after acid treatment. Reduction by hydrogen of monolayer vanadia in a $0.2-\mathrm{ML} \mathrm{V} / \mathrm{TiO}_{2}$ catalyst was studied by temperature-programmed reduction (TPR) at different heating rates. A one-site kinetic model is able to account for the TPR data, in spite of the presence of the monomeric and polymeric species. This indicates that these species could be considered equal with respect to the interaction with hydrogen. The activation energy was determined for the catalyst reduction $(98 \pm 5 \mathrm{~kJ} / \mathrm{mol})$. (c) 2002 Elsevier Science

Key Words: vanadia/titania catalyst; TPR in hydrogen; FTRaman spectroscopy; DRIFT; XPS; reduction kinetics modeling; partial oxidation.

\section{INTRODUCTION}

V/Ti-oxides are industrially important catalysts used for the partial oxidation of hydrocarbons and the selective reduction of $\mathrm{NO}_{x}$. They were also studied in some other catalytic reactions such as ammoxidation of alkylaromatics and oxidative dehydrogenation of hydrocarbons. During the last decade in situ physical methods have led to progress in the characterization of the surface-active sites of these

\footnotetext{
${ }^{1}$ To whom correspondence should be addressed. Fax: 41-21-693 3190. E-mail: lioubov.kiwi-minsker@epfl.ch.
}

catalysts. Under dehydrated conditions pure V/Ti-oxides contain isolated monomeric species, polymeric species, and bulk $\mathrm{V}_{2} \mathrm{O}_{5}$ in amorphous and crystalline states (1-7). In bulk $\mathrm{V}_{2} \mathrm{O}_{5}$, vanadium is octacoordinated, while in the monomeric and polymeric species, known as "monolayer vanadia," vanadium is tetracoordinated. It is shown (1) that the monolayer vanadia is formed at vanadia loadings, corresponding to the coverage of titania by $\mathrm{VO}_{x}$ species, less than 0.7 theoretical monolayer (ML). One theoretical monolayer is accepted as equal to $1 \mathrm{ML}=10$ $\mathrm{V}$-atoms $\mathrm{nm}^{-2}$ (4). Monolayer vanadia is found to be more active than bulk $\mathrm{V}_{2} \mathrm{O}_{5}$ in several reactions $(2,8,9)$. However, the reasons for its high catalytic activity and high selectivity toward partial oxidation products are still not clear.

Many reactions of partial oxidation have been shown to proceed via the Mars-van Krevelen mechanism including the steps of reduction of an oxide catalyst by a hydrocarbon and subsequent reoxidation by gaseous oxygen. Often a correlation is observed between the reducibility of vanadia determined by temperature-programmed reduction (TPR) in hydrogen and the catalytic activity. For example, the reducibility of vanadia supported on $\mathrm{TiO}_{2}, \mathrm{Al}_{2} \mathrm{O}_{3}, \mathrm{SiO}_{2}$ (10) and the activity trend of these catalysts in partial oxidation of methanol (8), ethane (11), toluene, $o$-xylene (12), and oxy-dehydrogenation of propane (13) correlate well between each other.

In spite of the similar coordination of the vanadium atom in the monomeric and polymeric species, their structure differs strongly due to the different length of the $\mathrm{V}-\mathrm{O}$ bonds. Moreover, contrary to the monomeric species, the polymeric species contain $\mathrm{V}-\mathrm{O}-\mathrm{V}$ oxygen bridges. Hence, different reducibility could be expected in hydrogen, i.e., different pre-exponential factors and/or activation energies. However, the TPR profile of the catalysts containing these two species usually consists of one peak (1). This shows that a differentiation between monomeric and polymeric vanadia by this method is difficult.

It is known that treatment of V/Ti-oxides in aqueous solutions of bases and acids results in partial removal of vanadia from the catalyst surface $(2,4,14-17)$. The dissolution of 
bulk $\mathrm{V}_{2} \mathrm{O}_{5}$ and polymeric species has been reported extensively (2). The surface concentrations of insoluble species has been shown to vary between 0.1 and $0.4 \mathrm{ML}$ (4) or may be higher than 1-ML coverage (16). The insoluble species catalyze oxidative dehydrogenation reactions (4), isopropanol conversion to acetone, and total $o$-xylene oxidation (2). The activity of the catalysts treated in nitric acid (containing only insoluble species) (16) was found to increase in the ammoxidation of methylpyrazine. Hence, the treatment in nitric acid activated the catalyst. However, a decrease in activity after such treatment was reported during $o$-xylene oxidation (2). Therefore, a characterization of the structure of insoluble vanadia is of interest in order to understand the parameters governing catalytic activity/selectivity. Spectroscopic information on the structure of insoluble species is quite limited (4). Recently Besselmann et al. (17) found only the monomeric species with tetracoordinated vanadium on the Eurocat V/Ti-oxide catalysts after treatment by $\mathrm{NH}_{4} \mathrm{OH}$ by Raman spectroscopy under dehydrated conditions. However, octahedral vanadium coordination followed from the ${ }^{51} \mathrm{~V}$ NMR studies of the $\mathrm{HNO}_{3}$-treated V/Ti-oxide catalyst (16).

The present work is aimed at the study of reducibility of the monomeric and polymeric species in hydrogen by TPR and diffuse reflectance infrared Fourier transform (DRIFT) spectroscopy. Kinetic simulation of the TPR experiments at different heating rates was performed to check whether it was possible to describe the kinetic results using a "one-site" model. The deconvolution of the TPR profiles of supported vanadia catalysts was performed earlier using several Gaussian-shaped curves (10) or multiple-sites models via first-order kinetics (18). To date, the kinetic parameters for the reduction of the vanadia monolayer supported on titania in hydrogen have not previously been determined from TPR experiments. A different solubility of monolayer and bulk vanadia in diluted $\mathrm{HNO}_{3}$ was used along with XPS and FT-Raman spectroscopy under a controlled atmosphere to investigate the structure of the vanadia species insoluble in nitric acid and the vanadium oxidation state.

\section{EXPERIMENTAL}

\subsection{Catalyst Preparation}

A $\mathrm{TiO}_{2}$ support was prepared by hydrolysis of the tetrapropylorthotitanate $(>98 \%$, Fluka). XRD and FTRaman spectroscopy studies showed that the support possesses an anatase structure. Potassium and sodium were not found in titania as measured by atomic emission spectroscopy $(<0.01 \mathrm{wt} \%)$. A monolayer catalyst with $1.8 \mathrm{wt} \%$ $\mathrm{V}$ was prepared via a well-known grafting technique $(4,5)$ by a three-step $\mathrm{VOCl}_{3}$ vapor deposition on the surface of $\mathrm{TiO}_{2}$, followed by hydroxylation and drying. An impregnated catalyst containing $11.1 \mathrm{wt} \% \mathrm{~V}$ was synthesized by a three-step wet impregnation with vanadium oxalate solution (synthesized from $\mathrm{V}_{2} \mathrm{O}_{5}(>99.6 \%$, Aldrich) and oxalic acid (>97\%, Fluka)). After calcination for $120 \mathrm{~min}$ at $723 \mathrm{~K}$ the BET surface areas of these catalysts were equal to 57 and $50 \mathrm{~m}^{2} \mathrm{~g}^{-1}$, respectively. The amount of vanadium in the catalysts corresponds to a 0.37 - and 2.6-ML coverage of titania by $\mathrm{VO}_{x}$ species $\left(1 \mathrm{ML}=10 \mathrm{~V}\right.$-atoms nm$\left.{ }^{-2}(4)\right)$. Surface impurities were not found by XPS on these catalysts. Two treatments of the catalysts for $25 \mathrm{~min}$ in excess of a $1.2 \mathrm{~N}$ aqueous solution of $\mathrm{HNO}_{3}$ were performed to obtain the samples with insoluble surface vanadia. After washing in deionized water, the catalysts were dried and calcined at $723 \mathrm{~K}$ for $30 \mathrm{~min}$ in air.

A sample with a smaller coverage by vanadia (0.2 ML) was prepared by wet impregnation of titania with vanadium oxalate solution. The vanadium concentration in this sample was equal to $1.2 \mathrm{wt} \%$, and the BET surface area was $76 \mathrm{~m}^{2} \mathrm{~g}^{-1}$.

\subsection{Spectroscopic Methods}

Infrared and Raman studies were performed using a FTIR, FT-Raman 2000 spectrometer (Perkin-Elmer). DRIFT or Raman spectroscopy in situ cells were attached to a setup described elsewhere (19). The FTIR spectrometer was equipped with a MCT detector, and $0.03 \mathrm{~g}$ of the catalyst ground in an agate mortar was placed in a SpectraTech 003-102 DRIFT cell with $\mathrm{CaF}_{2}$ windows. The DRIFT spectrum of the catalyst reduced in a hydrogen mixture $\left(673 \mathrm{~K}, 15 \mathrm{vol} \% \mathrm{H}_{2} / \mathrm{Ar}, 30 \mathrm{~min}\right)$ was taken in Ar at $573 \mathrm{~K}$. A single-beam spectrum of the preoxidized catalyst $\left(673 \mathrm{~K}, 20 \mathrm{vol} \% \mathrm{O}_{2} / \mathrm{He}, 30 \mathrm{~min}\right)$ measured at $573 \mathrm{~K}$ was taken as a background. The spectra were obtained by averaging 32 scans with a resolution of $4 \mathrm{~cm}^{-1}$.

A Nd-YAG laser, operating at $1064 \mathrm{~nm}$ with a varying power in the range of $10-750 \mathrm{~mW}$, was used in the FTRaman spectrometer. The Raman in situ cell is described elsewhere (7). Sixty-four scans were averaged with a resolution of $4 \mathrm{~cm}^{-1}$ to obtain a spectrum. The catalyst in the Raman cell was measured in the flow of dry $20 \mathrm{vol} \% \mathrm{O}_{2} / \mathrm{Ar}$ mixture $(60 \mathrm{ml}(\mathrm{STP}) / \mathrm{min})$ at 363 or $523 \mathrm{~K}$ after the pretreatment in this mixture at $673 \mathrm{~K}$ for $30 \mathrm{~min}$. The conditions of the pretreatment and measurement correspond to the dehydrated conditions (1).

XPS spectra of the catalysts were obtained in an Axis Ultra ESCA system (Kratos, Manchester) with monochromated $\mathrm{Al} K_{\alpha}$ radiation $(1486.6 \mathrm{eV})$ and X-ray power of $150 \mathrm{~W}$. The binding energies scale was referenced against $\mathrm{C} 1 \mathrm{~s}=285.0 \mathrm{eV}$ line. The $\mathrm{Ti}_{2 p_{3 / 2}}$-band maxima were found at the same position $(459.0 \mathrm{eV})$ for both studied samples.

\subsection{Temperature-Programmed Reduction}

A Micromeritics AutoChem 2910 analyzer with a quartz tubular flow reactor was used for the TPR studies. Hydrogen and other gases were analyzed by a quadrupole 
mass spectrometer (Thermostar, Pfeiffer Vacuum). The catalysts were pretreated under an oxidative atmosphere $\left(2 \mathrm{vol} \% \mathrm{O}_{2}\right.$, rest $\mathrm{He}$ ) at $673 \mathrm{~K}$ for $30 \mathrm{~min}$ and then cooled down in the same mixture to $323 \mathrm{~K}$. After a purge in Ar, the reactor was heated in the flow of ultrahigh purity $4 \mathrm{vol} \%$ of $\mathrm{H}_{2}$ in Ar with a constant heating rate. The measurement was performed at the same flow rate, $20.16 \mathrm{ml}(\mathrm{STP}) / \mathrm{min}$. The thermocouple was inserted into the middle of the catalytic bed. The catalyst charge corresponded to the same total surface area of the samples equal to $3.8 \mathrm{~m}^{2}$. The catalyst grains in the reactor were in the range of $0.35-0.5 \mathrm{~mm}$ in order to avoid diffusion limitations.

To study the reduction at four different heating rates, the same catalyst charge of $0.049 \mathrm{~g}$ of the fresh $0.2-\mathrm{ML}$ $\mathrm{V} / \mathrm{TiO}_{2}$ catalyst was placed into the reactor. The conversion of hydrogen at the maximum peak temperature $\left(T_{\max }\right)$ was lower than $25 \%$.

\section{RESULTS AND DISCUSSION}

The forms in which vanadia is present on the titania surface depend mostly on the vanadia surface concentration, which is generally expressed by titania coverage by $\mathrm{VO}_{x}$ groups. To determine different surface forms of vanadia with respect to their reactivity with hydrogen (TPR), the catalysts with the surface coverage by vanadia of 0.37 and 2.6 ML were mainly investigated before and after the treatment in diluted $\mathrm{HNO}_{3}$. These catalysts were also examined by FT-Raman spectroscopy under a controlled oxidative atmosphere without water vapor.

\subsection{Structure of Surface Vanadia and Vanadium \\ Oxidation State}

The FT-Raman spectrum of the $0.2-\mathrm{ML} \mathrm{V} / \mathrm{TiO}_{2}$ catalyst is shown in Fig. 1. The catalyst contains isolated monomeric

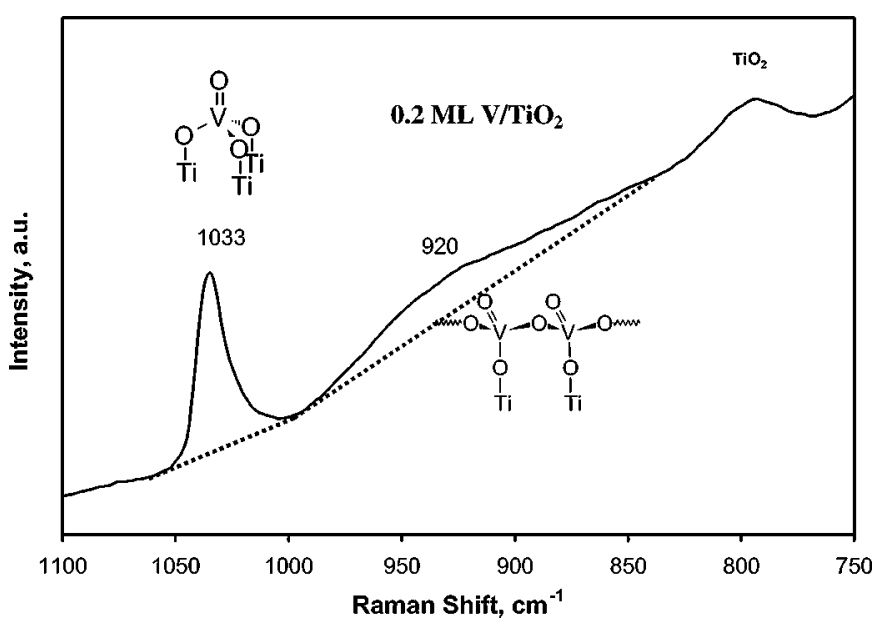

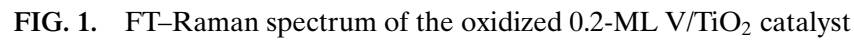
under dehydrated conditions.
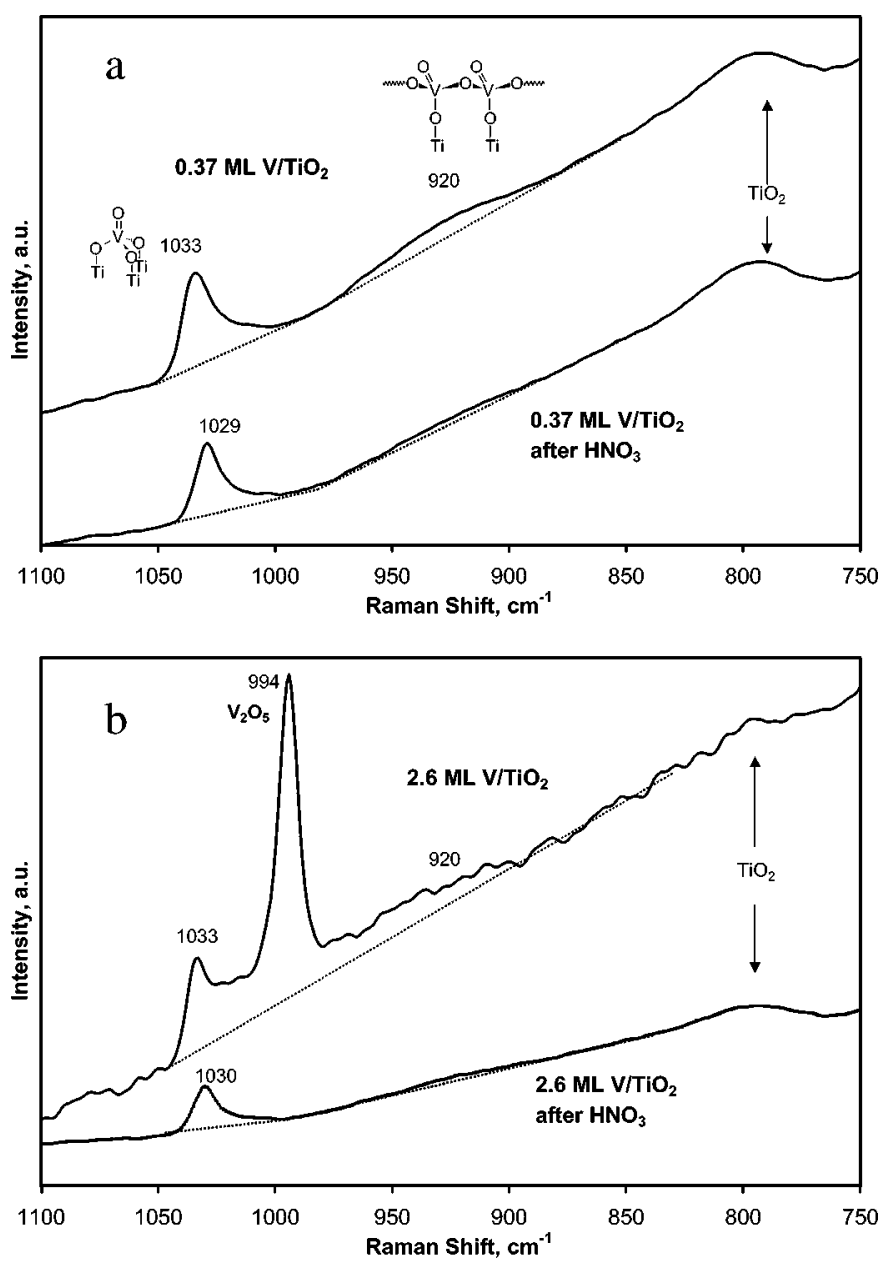

FIG. 2. FT-Raman spectra of the oxidized (a) 0.37- and (b) 2.6-ML $\mathrm{V} / \mathrm{TiO}_{2}$ catalysts under dehydrated conditions before and after treatment in diluted $\mathrm{HNO}_{3}$.

species $\left(1033 \mathrm{~cm}^{-1}\right)$ and polymeric metavanadate-like species $\left(920 \mathrm{~cm}^{-1}\right)$. In both of these species $\mathrm{V}^{5+}$ is tetracoordinated (1).

The FT-Raman spectrum of the $0.37-\mathrm{ML} \mathrm{V} / \mathrm{TiO}_{2}$ catalyst (Fig. 2a) is similar to that of the $0.2-\mathrm{ML} \mathrm{V} / \mathrm{TiO}_{2}$ catalyst (Fig. 1) and contains the monomeric as well as the polymeric species. The increase of the vanadium content from 0.37 to 2.6 ML leads to the appearance of bulk $\mathrm{V}_{2} \mathrm{O}_{5}$ species with a corresponding band at $994 \mathrm{~cm}^{-1}$ (Fig. 2b) together with the monomeric and polymeric species. These spectra are typical for pure V/Ti-oxides under dehydrated conditions $(3,20,21)$.

As already mentioned in the Introduction, vanadia supported on titania can be partially removed from the surface by dissolution in aqueous acids and bases $(2,4,14-17)$. The reactivity of different vanadia forms with acids depends on the strength of their interaction with the surface of titania. Treatment of the $2.6-\mathrm{ML} \mathrm{V} / \mathrm{TiO}_{2}$ catalyst by diluted $\mathrm{HNO}_{3}$ leads to the complete disappearance of the bulk $\mathrm{V}_{2} \mathrm{O}_{5}$ band (Fig. 2b). The monomeric species band intensity 


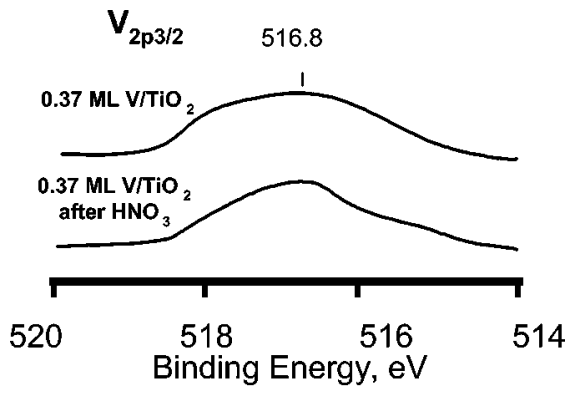

FIG. 3. XPS spectra (smoothed) of the $\mathrm{V}_{2 p_{3 / 2}}$ region of the oxidized 0.37-ML V/TiO 2 catalyst before and after treatment in diluted $\mathrm{HNO}_{3}$.

almost does not change. A drastic decrease of the polymeric species band (if not a complete removal) is observed in the spectra of both catalysts (Fig. 2). The possible presence of the polymeric species after acid treatment and calcination at $723 \mathrm{~K}$ could be a result of dehydration of the retained hydrated monomeric species at elevated temperature (22).

Additionally, it is observed that the $\mathrm{V}=\mathrm{O}$ band for the monomeric species shifts $3-4 \mathrm{~cm}^{-1}$ to lower wavenumbers after the acid treatment. This shift corresponds to a negligible increase of the $\mathrm{V}=\mathrm{O}$ interatomic distance (less than $0.002 \AA(23))$ and is due to the decrease of vanadia concentration (24). The accompanied increase of the Ti-OH group concentration (discussed later) probably provides increased hydrogen bonding with oxygen of the vanadyl groups and explains the lengthening of the $\mathrm{V}=\mathrm{O}$ bond. Similar effects were found during direct water vapor treatment of vanadia catalysts $(1,20)$.

XPS measurements of the $0.37-\mathrm{ML} \mathrm{V} / \mathrm{TiO}_{2}$ catalyst before and after treatment in $\mathrm{HNO}_{3}$ and calcination at $723 \mathrm{~K}$ were also performed. The $\mathrm{V}_{2 p_{3 / 2}}$ signals were noisy because of the small concentration of vanadium in the studied catalysts. This explains the asymmetric shape of the observed peaks, but it is clearly seen (Fig. 3) that the main oxidation state of vanadium is similar in both samples $(516.8 \mathrm{eV})$ and corresponds to that of $\mathrm{V}^{5+}(25)$. The $\mathrm{V} /(\mathrm{Ti}+\mathrm{V})$ atomic surface ratio was observed to decrease after the treatment, but was not quantified due to the high experimental error.

Hence, the polymeric and $\mathrm{V}_{2} \mathrm{O}_{5}$ species are removed during the acid treatment. Vanadium in all species found in the catalysts after the treatment is pentavalent and tetracoordinated contrary to the results (16), where only octacoordinated vanadium was determined by ${ }^{51} \mathrm{~V}$ NMR. The difference may be due to a much higher concentration of insoluble species, in the latter case explained by the presence of impurities in the catalyst as well as due to spectroscopic measurements under ambient conditions in the presence of water vapor.

\subsection{Reducibility of Surface Vanadia Species by Hydrogen}

TPR profiles of the same catalysts before and after the $\mathrm{HNO}_{3}$ treatment are shown in Figs. $4 \mathrm{a}$ and $4 \mathrm{~b}$. It is seen that the amount of hydrogen consumed for the treated catalysts decreased two and seven times, respectively, for the 0.37- and 2.6-ML V/ $/ \mathrm{TiO}_{2}$ catalysts. This indicates that vanadia is partially removed in $\mathrm{HNO}_{3}$ in accordance with the FT-Raman spectra (Fig. 2). The surface vanadia concentration corresponds to the values reported by GrzybowskaSwierkosz (4) in the range of 0.1-0.4 ML.

Another important observation is that $T_{\max }$ for the reduction of the catalysts after the acid treatment shifts to lower temperatures (770-780 K) independently of the initial coverage by vanadia ( 0.37 or $2.6 \mathrm{ML})$. According to the FT-Raman spectroscopy data the main species retained on the surface is the monomeric species (Fig. 2). Hence, $T_{\max }$ for the reduction of this species must be equal to $770-780 \mathrm{~K}$ or be slightly lower. The latter suggests the existence of some amount of the polymeric species reducible at a higher temperature than the monomeric species.

The difference TPR profile corresponding to the removal of mainly $\mathrm{V}_{2} \mathrm{O}_{5}$ from the 2.6-ML V/TiO 2 catalyst has a maximum at $852 \mathrm{~K}$ (Fig. 4b). Bulk crystalline $\mathrm{V}_{2} \mathrm{O}_{5}$ can be reduced only at much higher temperature $(>950 \mathrm{~K})(5,6,26)$.
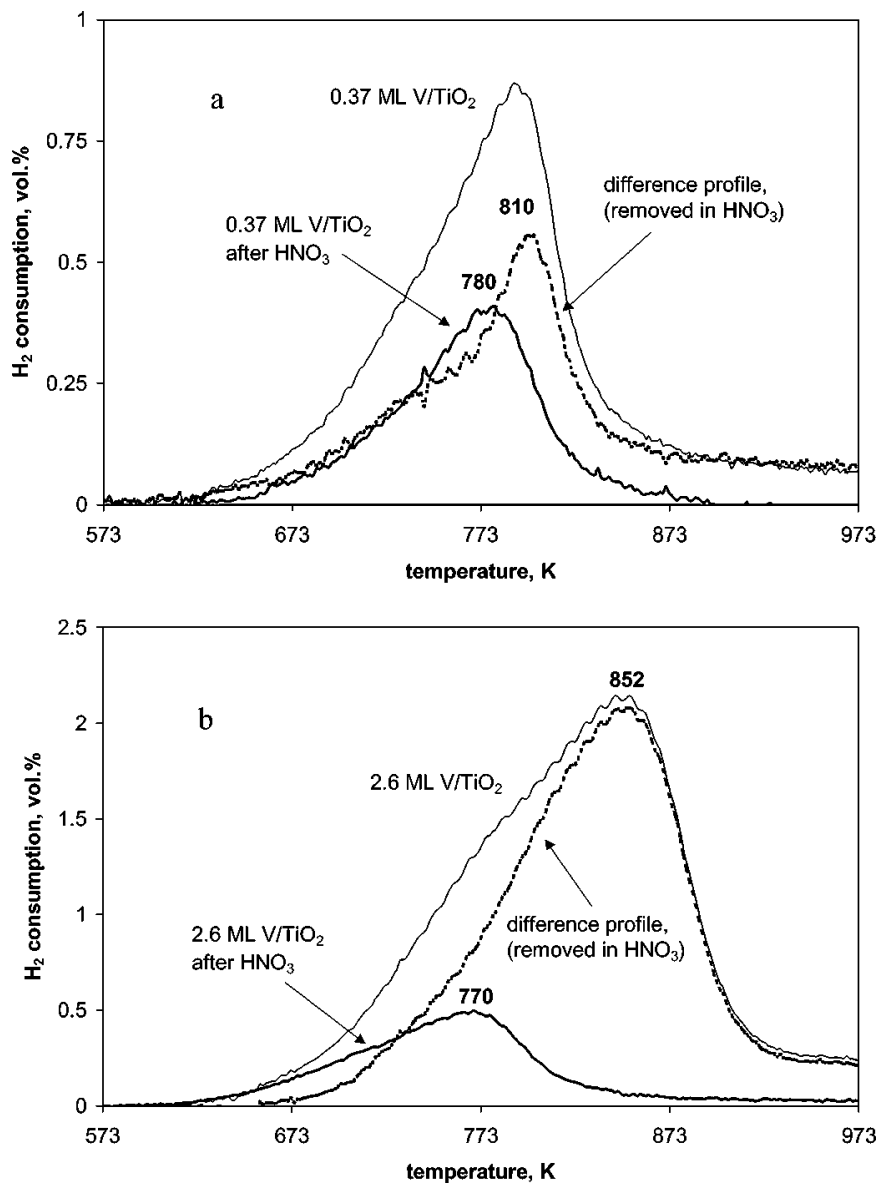

FIG. 4. TPR profiles of the (a) 0.37- and (b) 2.6-ML V/TiO 2 catalysts before and after treatment in $\mathrm{HNO}_{3}$. Total flow rate of the $4 \mathrm{vol} \% \mathrm{H}_{2} / \mathrm{Ar}$ mixture: $20.16 \mathrm{ml}(\mathrm{STP}) / \mathrm{min}$, heating rate $20 \mathrm{~K} / \mathrm{min}$. 
Hence, the peak with a maximum at $852 \mathrm{~K}$ was assigned to the reduction of amorphous $\mathrm{V}_{2} \mathrm{O}_{5}$. The difference between bulk crystalline and amorphous $\mathrm{V}_{2} \mathrm{O}_{5}$ consists of the fact that the latter is present in the form of nanocrystalline particles and/or thin layers. The maximum of difference pro-

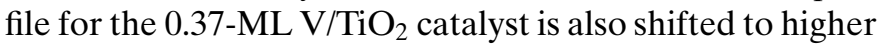
temperatures $(810 \mathrm{~K})$ with respect to $T_{\max }$ for the reduction of the monomeric species ( $\leq 770-780 \mathrm{~K}$ ) (Fig. 4a). $T_{\max }$ at $810 \mathrm{~K}$ is assigned to the reduction of the polymeric species as the acid treatment of the $0.37-\mathrm{ML} \mathrm{V} / \mathrm{TiO}_{2}$ catalyst removes mainly the polymeric species (Fig. 2a).

Due to the $\mathrm{HNO}_{3}$ treatment, it was possible to estimate the $T_{\max }$ of the monomeric species reduction. The monomeric species seems to be easily reducible in hydrogen. $T_{\max }$ for the reduction of the polymeric species is slightly higher $(30-40 \mathrm{~K})$. The reduction of amorphous bulk $\mathrm{V}_{2} \mathrm{O}_{5}$ takes place at about $70-80 \mathrm{~K}$ higher than that observed in the case of the monomeric species. Thus with an increase coverage of titania by vanadia and vanadia polymerization degree, the TPR peak should shift to higher temperatures in accordance with the literature data (27-29). This trend, however, cannot be extended to vanadia on other supports because of the change in the vanadiasupport interaction dependent on the electronegativity of the support cation $(8,11)$. Contrary to the reduction of vanadia/titania catalysts Stobbe-Kreemers et al. (30) found a decrease of $T_{\max }$ with increased vanadia loading on alumina, which was assigned to an easier reduction of the polymeric compared to the monomeric species. Hence, the nature of the support affects the reducibility of the vanadia species mainly via the $\mathrm{V}-\mathrm{O}-\mathrm{Me}(\mathrm{Me}=\mathrm{Ti}, \mathrm{Al}, \mathrm{Mg}$, etc. $)$ bonds $(8,10,11,13)$.

\subsection{Kinetics and Modeling of the Reduction of Monolayer Vanadia by Hydrogen}

In order to determine the energy of activation of the reduction of only the monolayer vanadia, the $0.2-\mathrm{ML} \mathrm{V} / \mathrm{TiO}_{2}$ catalyst which does not contain any $\mathrm{V}_{2} \mathrm{O}_{5}$ species (Fig. 1) was reduced in hydrogen at different heating rates. The experimental TPR curves are shown in Fig. 5. The increase of the heating rate from 4.99 to $63.7 \mathrm{~K} / \mathrm{min}$ results in a shift of $T_{\max }$ to higher values by more than $100 \mathrm{~K}$. The activation energy for the reduction can be estimated by (31)

$$
\ln \left(\beta / T_{\max }^{2}\right)=-E_{a} /\left(8.314 T_{\max }\right)+\text { const, }
$$

where $\beta$ is the heating rate $(\mathrm{K} / \mathrm{min}), E_{a}$ is the activation energy of reduction $(\mathrm{J} / \mathrm{mol})$, and 8.314 is the universal gas constant $(\mathrm{J} /(\mathrm{mol} \mathrm{K}))$. The $E_{a}$ value was estimated equal to $98 \pm 5 \mathrm{~kJ} / \mathrm{mol}$ (Fig. 6).

As the conversion of hydrogen was relatively low, the equation for the mass balance of hydrogen in a gradientless reactor can be used; for example,

$$
\Delta y Q_{n}=-R m Z_{0},
$$

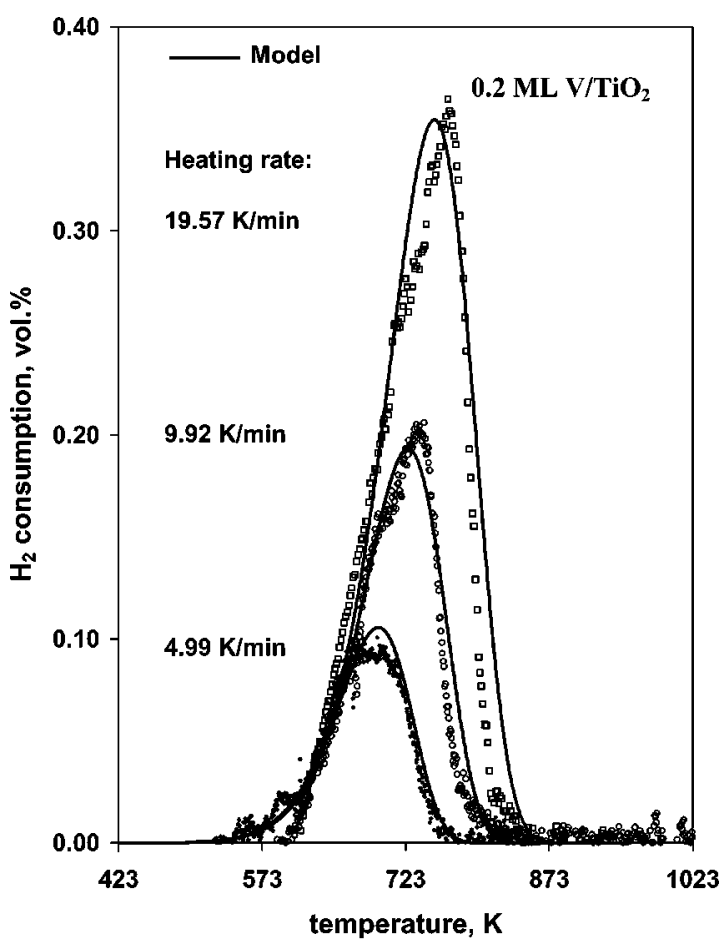

FIG. 5. TPR profiles of the $0.2-\mathrm{ML} \mathrm{V} / \mathrm{TiO}_{2}$ catalyst at different heating rates (points, experiments; curves, simulation using a one-site model). Total flow rate of the $4 \mathrm{vol} \% \mathrm{H}_{2} /$ Ar mixture is $20.16 \mathrm{ml}$ (STP)/min.

where $\Delta y$ is the molar fraction of the consumed hydrogen (difference between the molar fraction of hydrogen at the reactor inlet and reactor outlet), $Q_{n}$ is the total molar flow $(\mathrm{mol} / \mathrm{s}), m$ is the mass of the catalyst $(\mathrm{kg}), R$ is the rate of hydrogen consumption related to the moles of reducible sites $(1 / \mathrm{s})$, and $Z_{0}$ is the total concentration of reducible sites in the catalyst $(\mathrm{mol} / \mathrm{kg})$.

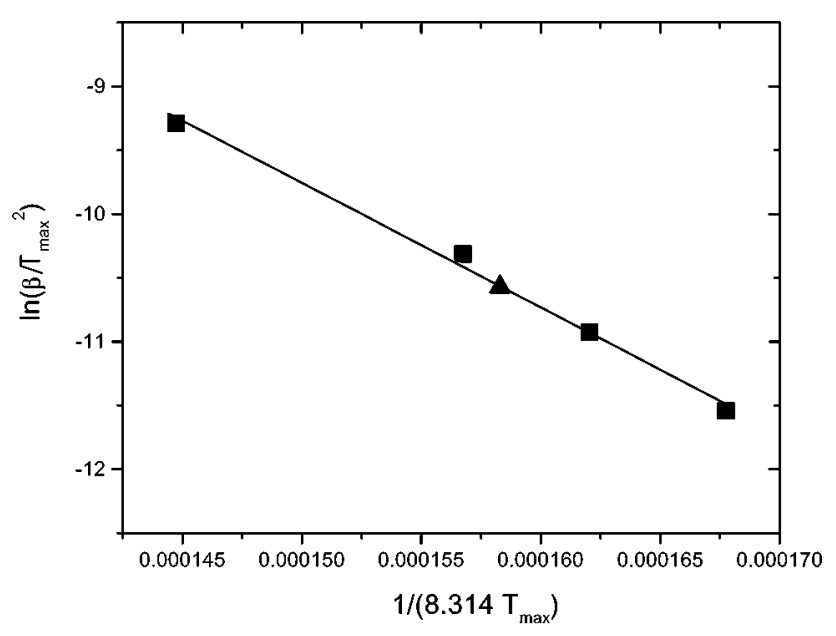

FIG. 6. Determination of activation energy for the reduction of the $0.2-\mathrm{ML} \mathrm{V} / \mathrm{TiO}_{2}$ catalyst in hydrogen at different heating rates (squares, total flow rate $20.16 \mathrm{ml}$ (STP)/min, triangles, $10.19 \mathrm{ml}$ (STP)/min). 
During the reduction of the 0.2- and 0.37-ML V/TiO catalysts the $\mathrm{O} / \mathrm{V}$ atomic ratio was found to be $1.6 \mathrm{O}$ atom to $1 \mathrm{~V}$-atom. For the 2.6-ML V/TiO 2 catalyst containing bulk vanadia this ratio was found to be lower (0.95). The literature $\mathrm{O} / \mathrm{V}$ ratios were reported in the range of 1-1.53. They were equal to 1 (32), 1.1-1.2 (3), 1.5 (33), and $1.53(10)$. The values higher than 1 were explained by the partial transformation of $\mathrm{V}^{5+}$-containing vanadia into the $\mathrm{V}^{2+}$-containing species (33). Another explanation is that some part of hydrogen may be retained on the surface in the form of hydroxyl groups attached to the reduced vanadia species as proposed by Haber et al. (32) and Went et al. (3). Both assumptions need further experimental confirmation.

The processes of reduction of the monolayer vanadia species on the titania support are not complicated by subsurface-surface diffusion as in the case of the reduction of bulk crystalline $\mathrm{V}_{2} \mathrm{O}_{5}(26)$. Thus the rate equation of the surface vanadia reduction was assumed to be first order in hydrogen pressure and in coverage by reducible species $\left(\theta=Z / Z_{0}\right)$; for example,

$$
R=d \theta / d t=k_{0} p \theta \exp \left(-E_{a} /(8.314 T)\right)
$$

where $k_{0}$ is a preexponentional factor $(1 /(\mathrm{Pa} \mathrm{s})), t$ is the time (s), $T$ is the temperature as a function on time $(T=323+\beta t)(\mathrm{K}), Z$ is the concentration of reducible sites at any time $(\mathrm{mol} / \mathrm{kg})$, and $p$ is the partial pressure of hydrogen $(\mathrm{Pa})$.

The simulation of the TPR curves at different heating rates was performed using Berkeley Madonna software (Berkeley, CA). The found value of $E_{a}=97.6 \mathrm{~kJ} / \mathrm{mol}$ (Fig. 6) was used, and only the value of the preexponentional factor was varied. It was estimated to be equal to $4.0 \mathrm{~Pa}^{-1} \cdot \mathrm{s}^{-1}$. It is seen from Fig. 5 that the simulated TPR peaks width at half-height and the amount of the consumed hydrogen, as seen by the area under the curve, correspond well to the experimental data. The shapes of the simulated and experimental curves turned out to be slightly different. Experimental curves were less symmetric and characterized by a steep decrease in temperature after the maximum. The presence of different reducible sites on the catalyst surface could explain the latter fact. However, the application of a "two-sites" model did not significantly improve the simulation to fit to the experimental data.

\subsection{DRIFT Study of the Surface Oxygen Involved in the Vanadia Reduction by Hydrogen}

To determine what happens with surface vanadia species and hydroxyl groups during the reduction in hydrogen, a DRIFT study was performed, and the spectrum was related to the spectrum of the catalyst in the oxidized state.
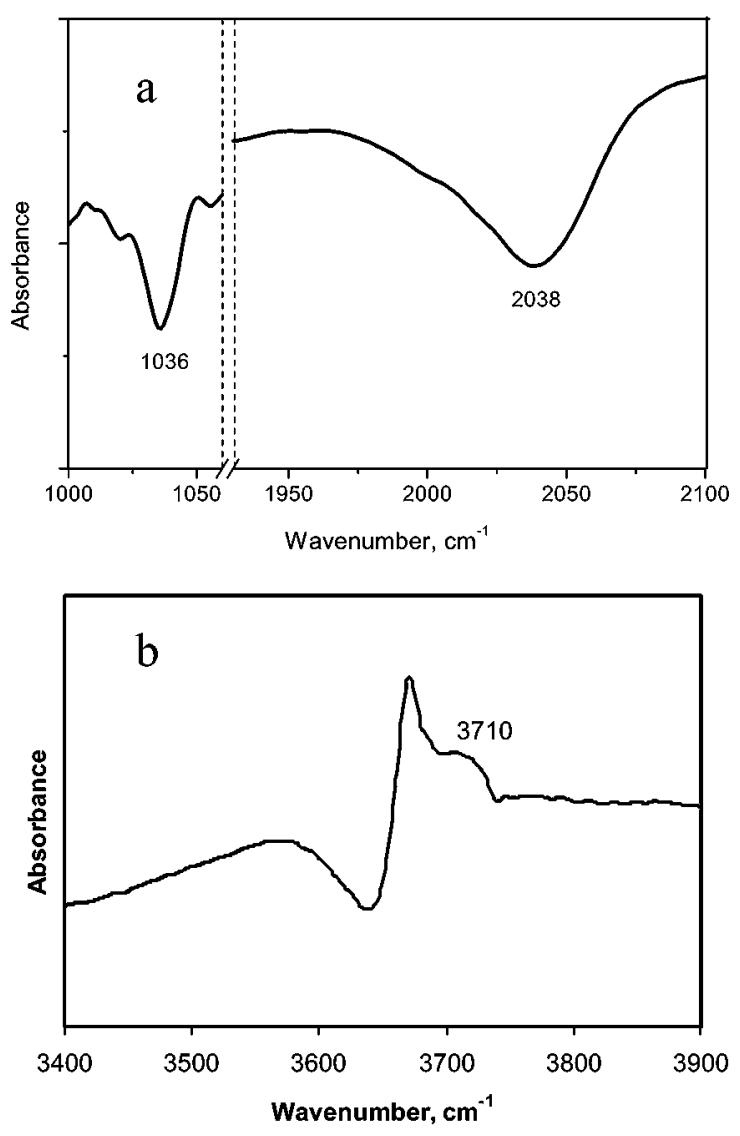

FIG. 7. DRIFT spectra of the vanadia (a) and hydroxyl (b) regions of the $0.37-\mathrm{ML} \mathrm{V} / \mathrm{TiO}_{2}$ catalyst after the reduction in the $15 \mathrm{vol} \% \mathrm{H}_{2} / \mathrm{Ar}$ mixture at $673 \mathrm{~K}$ for $30 \mathrm{~min}$. The measurement was performed in $\mathrm{Ar}$ at $573 \mathrm{~K}$. The spectrum of the oxidized catalyst is taken as a background.

The negative absorbance bands at 1036 and $2038 \mathrm{~cm}^{-1}$ ob-

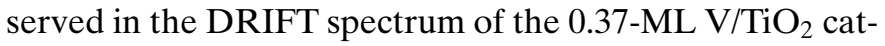
alyst (Fig. 7a) after $30 \mathrm{~min}$ of reduction at $673 \mathrm{~K}$ correspond to the $\mathrm{V}=\mathrm{O}$ stretching band and its first overtone in the monomeric species, respectively (34-36). The negative bands indicate the reduction of the monomeric species under these relatively mild conditions. No new vanadia bands appear in the region of interest after the reduction. The region below $950 \mathrm{~cm}^{-1}$, characteristic for the polymeric species, could not be studied because of a strong absorbance by the titania support.

The hydroxyl group region in the DRIFT spectrum shown in Fig. $7 b$ possesses negative $\left(\sim 3650 \mathrm{~cm}^{-1}\right)$ as well as positive features $\left(\sim 3670\right.$ and $\left.3710 \mathrm{~cm}^{-1}\right)$. The total picture implies the shift of the hydroxyl region to the higher wavenumbers. This is indicative of hydroxyl groups more basic on the reduced catalyst if compared to the oxidized catalyst. Dines et al. (37), after hydrogen reduction of the vanadia/titania catalyst, found the disappearance of the Brønsted sites by ammonia and pyridine adsorption. The positive bands at 3670 and $3710 \mathrm{~cm}^{-1}$ indicate the appearance of new hydroxyl groups or an increase of their 
concentration after the reduction. These two bands are observed in the spectrum of a pure titania-anatase used as a support $(35,38)$.

Topsoe et al. (35) assigned the $3650-\mathrm{cm}^{-1}$ band to the hydroxyl groups attached to vanadia sites. Upon the reduction the disappearance of this band and the appearance of the 3670 - and $3715-\mathrm{cm}^{-1}$ bands assigned to the hydroxyl groups of titania are reported. This is explained by the agglomeration of vanadia species during reduction and a liberation of some titania sites involved in the formation of the monomeric vanadia species. A similar mechanism was proposed earlier for the vanadia/alumina catalyst by Sobalik et al. (39). Recently, using in situ XAFS experiments, Ruitenbeek et al. (40) demonstrated the possibility of $\mathrm{V}^{3+}$ formed upon reduction not to agglomerate but to migrate into the bulk of the alumina support. This process was reversible, as the isolated monomeric species were formed again upon reoxidation. The present study shows evidence for the disappearance of $\mathrm{V}=\mathrm{O}$ groups upon the reduction by hydrogen and the formation of Ti-OH groups. However, the nature of hydroxyl groups associated with supported vanadia species and the structure of reduced vanadia species need further clarification.

\section{CONCLUSIONS}

Three types of vanadia species were determined on vanadia/titania catalysts consisting of $0.2-2.6 \mathrm{ML}$ of $\mathrm{VO}_{x}$ on the titania surface. Their reducibility in hydrogen was characterized by the peak maximum in the TPR profiles indicating isolated monomeric species: $(\leq 770-780 \mathrm{~K})$, polymeric species $(810 \mathrm{~K})$, and bulk amorphous $\mathrm{V}_{2} \mathrm{O}_{5}(852 \mathrm{~K})$. The monomeric species was the easiest to reduce.

During the reduction, the $\mathrm{V}=\mathrm{O}$ bond of the monomeric species with tetracoordinated vanadium was observed to disappear, as shown by DRIFT spectroscopy. A formation of new hydroxyl groups with a basic character probably associated with titania was observed.

A "one-site" kinetic model describes accurately the TPR profiles obtained during the reduction of the $0.2-\mathrm{ML}$ $\mathrm{V} / \mathrm{TiO}_{2}$ catalyst in hydrogen, containing the monomeric and polymeric vanadia. This indicates that these species could be considered equal with respect to the interaction with hydrogen. An activation energy of $98 \pm 5 \mathrm{~kJ} / \mathrm{mol}$ was obtained for the reduction of monolayer vanadia.

Bulk amorphous $\mathrm{V}_{2} \mathrm{O}_{5}$ and polymeric vanadia were soluble in nitric acid and removed by acid from the surface. The monomeric species was the most stable in diluted $\mathrm{HNO}_{3}$ suggesting strong attachment to the titania support.

The state of vanadium in the preoxidized catalysts was mainly pentavalent, as shown by XPS, and did not change after acid treatment.

\section{ACKNOWLEDGMENTS}

The authors thank the Swiss National Science Foundation for financial support. XPS measurements by N. Xanthopoulos (DM-EPFL) and useful discussions with Dr. B. Monnerat (LGRC-EPFL) are gratefully acknowledged.

\section{REFERENCES}

1. Wachs, I. E., and Weckhuysen, B. M., Appl. Catal. A Gen. 157, 67 (1997).

2. Bond, G. C., and Vedrine, J. C., Catal. Today 20, 171 (1994).

3. Went, G. T., Leu, L.-J., and Bell, A. T., J. Catal. 134, 479 (1992).

4. Grzybowska-Swierkosz, B., Appl. Catal. A Gen. 157, 263 (1997).

5. Bond, G. C., Appl. Catal. A Gen. 157, 91 (1997).

6. Bulushev, D. A., Rainone, F., Kiwi-Minsker, L., and Renken, A., Langmuir 17, 5276 (2001).

7. Bulushev, D. A., Kiwi-Minsker, L., Zaikovskii, V. I., and Renken, A., J. Catal. 193, 145 (2000).

8. Deo, G., and Wachs, I. E., J. Catal. 146, 323 (1994).

9. Courcot, D., Grzybowska, B., Barbaux, Y., Rigole, M., Ponchel, A., and Guelton, M., J. Chem. Soc., Faraday Trans. 92, 1609 (1996).

10. Arena, F., Frusteri, F., and Parmaliana, A., Appl. Catal. A Gen. 176, 189 (1999).

11. Banares, M. A., Martinez-Huerta, M. V., Gao, X., Fierro, J. L. G., and Wachs, I. E., Catal. Today 61, 295 (2000).

12. van Hengstum, A. J., van Ommen, J. G., Bosch, H., and Gellings, P. J., Appl. Catal. 8, 369 (1983).

13. Lemonidou, A. A., Nalbandian, L., and Vasalos, I. A., Catal. Today 61, 333 (2000).

14. Centi, G., Giamello, E., Pinelli, D., and Trifiro, F., J. Catal. 130, 220 (1991).

15. Nogier, J. P., Catal. Today 20, 23 (1994).

16. Bondareva, V. M., Andrushkevich, T. V., and Lapina, O. B., Catal. Today 61, 173 (2000).

17. Besselmann, S., Loffler, E., and Muhler, M., J. Mol. Catal. A Chem. 162, 401 (2000).

18. Koranne, M. M., Goodwin, J. G., and Marcelin, G., J. Catal. 148, 369 (1994).

19. Bulushev, D. A., Kiwi-Minsker, L., and Renken, A., Catal. Today 57, 231 (2000).

20. Jehng, J.-M., Deo, G., Weckhuysen, B. M., and Wachs, I. E., J. Mol. Catal. A Chem. 110, 41 (1996).

21. Olthof, B., Khodakov, A., Bell, A. T., and Iglesia, E., J. Phys. Chem. B 104, 1516 (2000).

22. Balzhinimaev, B. S., and Pinaeva, L. G., Kinet. Catal. 36, 52 (1995).

23. Hardcastle, F. D., and Wachs, I. E., J. Phys. Chem. 95, 5031 (1991).

24. Wachs, I. E., Catal. Today 27, 437 (1996).

25. Nogier, J. P., and Delamar, M., Catal. Today 20, 109 (1994).

26. Bosch, H., Kip, B. J., van Ommen, J. G., and Gellings, P. J., J. Chem. Soc., Faraday Trans. I 80, 2479 (1984).

27. Matralis, H. K., Papadopoulou, C., Kordulis, C., Elguezabal, A. A., and Corberan, V. C., Appl. Catal. A Gen. 126, 365 (1995).

28. Baiker, A., Dollenmeier, P., Glinski, M., and Reller, A., Appl. Catal. 35, 351 (1987).

29. Bond, G., and Tahir, S. F., Appl. Catal. 71, 1 (1991).

30. Stobbe-Kreemers, A. W., van Leerdam, G. C., Jacobs, J.-P., Brongersma, H. H., and Scholten, J. J. F., J. Catal. 152, 130 (1995).

31. Hurst, N. W., Gentry, S. J., Jones, A., and McNicol, B. D., Catal. Rev.Sci. Eng. 24, 233 (1982).

32. Haber, J., Kozlowska, A., and Kozlowski, R., J. Catal. 102, 52 (1986). 
33. Malet, P., Munoz-Paez, A., Martin, C., and Rives, V., J. Catal. 134, 47 (1992).

34. Busca, G., Centi, G., Marchetti, L., and Trifiro, F., Langmuir 2, 568 (1986).

35. Topsoe, N.-Y., Topsoe, H., and Dumesic, J. A., J. Catal. 151, 226 (1995).

36. Scharf, U., Schneider, M., Baiker, A., and Wokaun, A., J. Catal. 149, 344 (1994).
37. Dines, T. J., Rochester, C. H., and Ward, A. M., J. Chem. Soc., Faraday Trans. 87, 1611 (1991).

38. Primet, M., Pichat, P., and Mathieu, M. V., J. Phys. Chem. 75, 1216 (1971).

39. Sobalik, Z., Kozlowski, R., and Haber, J., J. Catal. 127, 665 (1991).

40. Ruitenbeek, M., van Dillen, A. J., de Groot, F. M. F., Wachs, I. E., Geus, J. W., and Koningsberger, D. C., Topics Catal. 10, 241 (2000). 